一样, 从而將使农策配䈯的条件和农莱配置的面浣发 生革命性的变化。这个䦗題虽然目前还不太近切，但 不久的將来一定会出現。

5. 在消灭工农美别和城乡美别的前景下苟 动 盗 源的合理利用与居民点合理跑置問题：人民公浇化以 后笑行“办农亦工”的多面手运动和“工农棓学兵”全面 耛合，多部卧桱济齐头扑进，这将逐步改变旧有的社会 分工，特別是使“工業人口”同“农業人口”的美别逐濑 㩁小，以至趋于洞头。这任劳动資源的利用、劳动力 的部师分配和劳动力季节本衡閏題上山現了完全新的

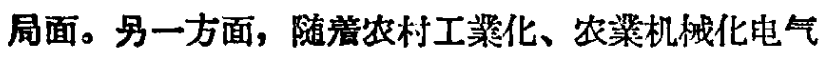
化、城市和农村的逐步走问园林化的結染，农村的展 民点將从小农經济时代的“小桥流水人家”的分散落后

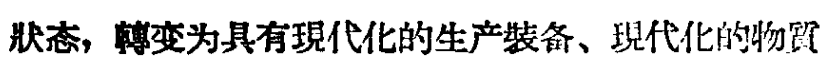
文化毁施的比較集中的新型居民点, 而战材则不仪山 消費据点变为現代化的生产中心，更將且㺍照污罚的 生活环境轉变为被光分粶化的风景幽美的花园城。这 將使城方与乡村間現存的生产与生活条件的美別逐步 㴼小而趋于消灭。但在我国这样一个人口如此众多, 环境如此多样化的大国里, 如何实現这种差別的消 灭, 如何改遭旧居民点和重新配琵新居民点, 不可能 在各地方都采用千篇一律的格式，这些問題都是很狩 出的值得研究的問題。

以上这些問題具有共同的特点:(1)它们都是我国 生产笑践中已經出現和將要计現的重大䦕题，也是党 和政府以及广大草众迫切需要解决拌正在着手解决的 新問題。为了使人民昰众的冲天干勁同实事求是的科 学分析精合起来, 需要进行大量的科学䂥究, 科学工 作者是不能袖手旁覌的。(2) 这些間題都和各地的 然湮济条件有密切联系, 具有强烈的地域性, 因而地 理工作者特别是經济地理工作者，有可能在这些閣题 的研究上发押作用。(3) 这些問題大多具有中国的特 点, 通过这些問題的研究，可以从实践中总結山一些
特有的規律性来，以任务需学科，从而为建立我国的 独㓣性的經济地理学打开局闻, 贷定基础。例如, 通 过对于人中小結合、士洋扑举的工瑟配置的研究, 缏

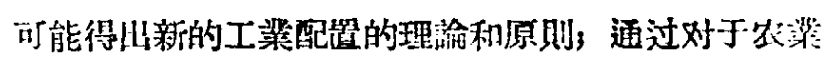

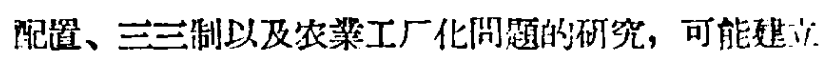

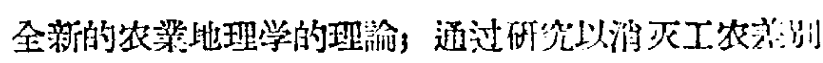
和城乡差别为目的的实践，会创立新的人口地理学;

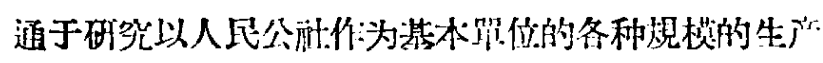

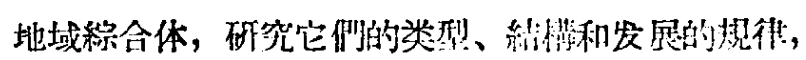

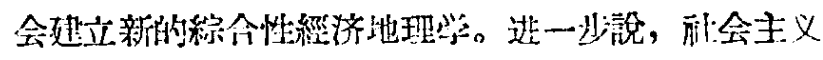

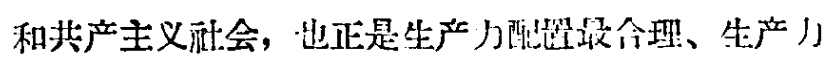

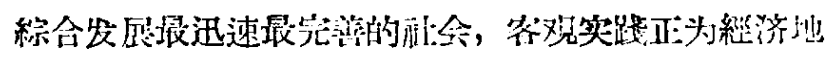

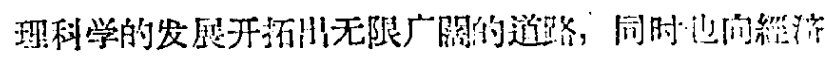

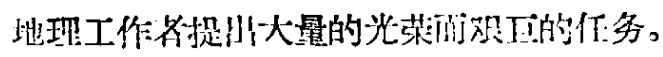

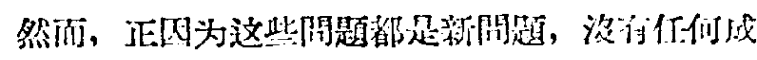

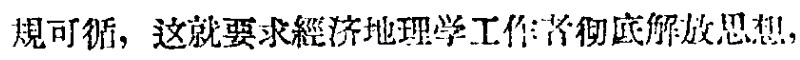

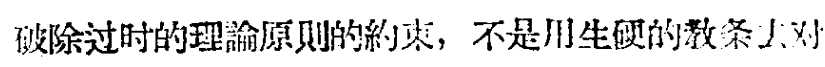

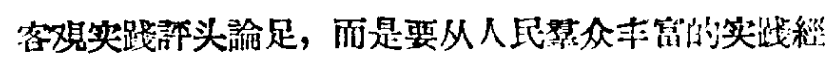
驗中去发現規律，找11理諭孙。为了解决实践問题， 要冰經地地工作者把單紝搭述现出的工作方式改变

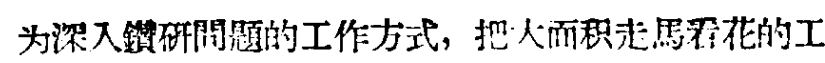
作方式改变为在小地区㧛細研究的工作方式，而作

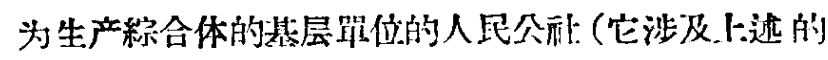
一切問題)应該是研究工作报好的基点。为了这个 11 的, 不仅要求所有地理工作孝政治脚饰, 通力协作,

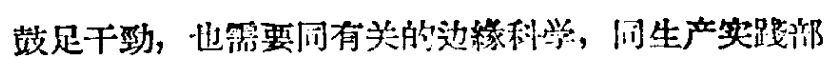

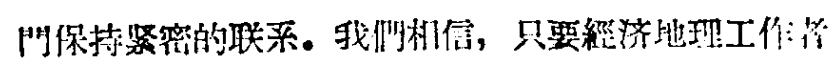

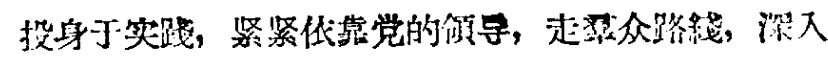
䥊研党的方針政策，研究各地区的自然經济条作和人 民章众无比丰富的經驗，就一定能够在我口阶l会主义

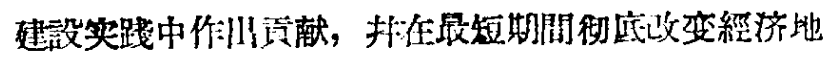
理学的落后面貌, 瀷这们科学走进世界先进科学的行 ziil。

\title{
从中国大地構造的特征談中国大地 構造單位的命名
}

\author{
張文 估 \\ (中国科学院地筫研究所)
}

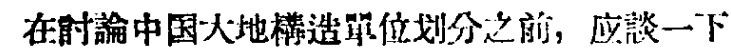
国大地搼造的特点。

（1）中国地台比一般地台(如领罗斯地台、北) 地台等)活动, 而地慒比一般地慒(如吕拈尔地槽、阿

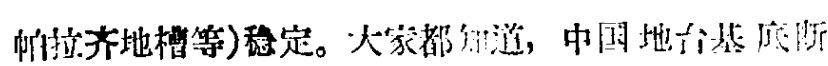

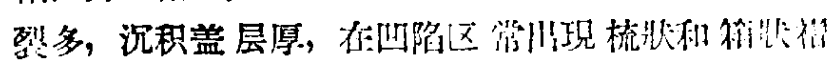

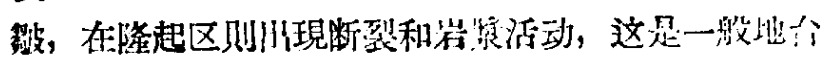

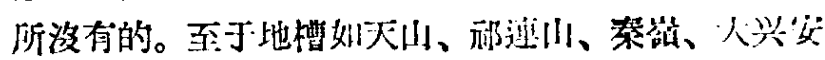




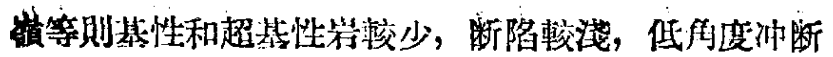
层不多 3 由于該处地壳粘一梦性校小，不易一下而沉

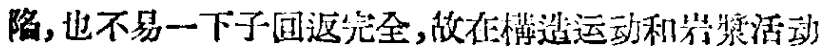

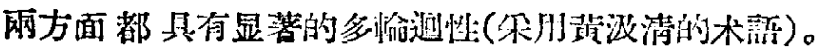

（2）基底块议断裂控制着汇积筑层的发有。深断

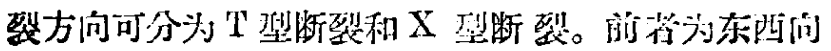
和南北问, 与 H. C. 沙特特断基的证问断裂相当, 可与

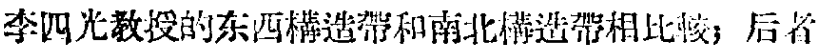

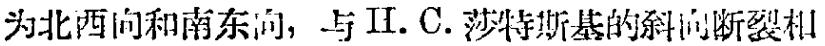

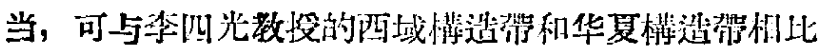

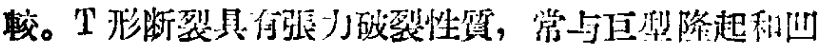

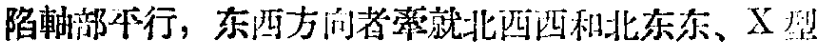

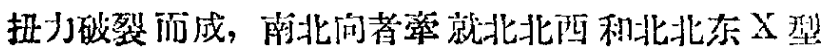

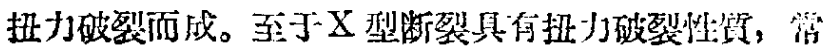
科切巨梨隆起和四陷軸部。

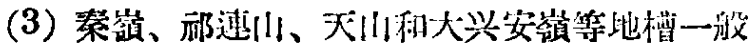
是在前祳旦紀基底上目深断陷而形成的，它們一般 $\mathrm{F}^{\circ}$ 古生代沉陷，上古生代回返。南䢵泟山的海酩地慒、 东北太平領不岑二选紀地槽以及那乎哈达繁中生代地

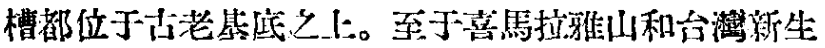

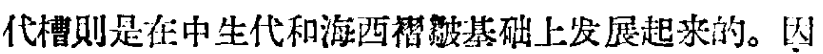
此，中国地台在桨种意义上可称为破磁琖余治台。

（4）中国的古地台（太古代和元占代）和新地台 （古生代、中生代和新生代)都有活化現像。活化的) 式有二:(1)在隆起区以断裂和岩愁活动为主，如华夏

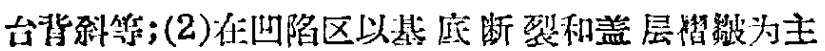
(如四川和鄂黭台问科等)。中国显著的古生代活化区 有:汇南台背科、北山块断浩、东北台块、横断山块断惯 等。显著的中生代活化区有: 大兴安䫈和天山等古生代 新地台、华南台块以及华北台块和酒藏台块的边螕地 区等。显著的新生化活化区有：柴达小、塔里朴和西 藏台块以及䢵邀川占生代新地台边㴚地区。

在考虑以上所說的我国大地權造泊四个主要特点 之后，我阿在划分大地模浩的，就必須注意到基底断

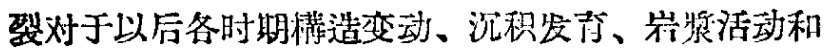
变質作肋的影响，正同断裂中的横们断裂和縱问断裂 对于中国地台和比槽的发青起显河的控测作用，如在 东部横何断裂分开东北、华北和华简台块; 在西部控

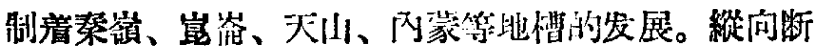
裂划分出中国东唒㞹大部分在大地模造上的不同：賀 蔄山、六盤川、龙" 以西则以地 槽区为主。科向 断裂对于我国大地構造 的发展也具有强烈约影响，在中国东部的深断裂以 北东和北北东问为主，如东北台块、华北台块和华南

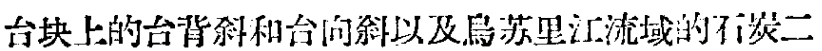

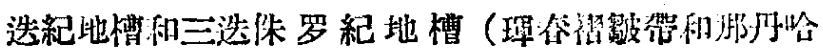

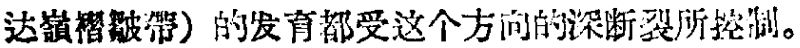

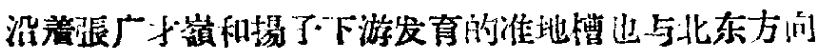

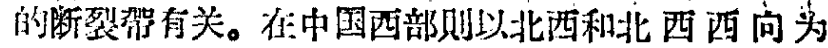

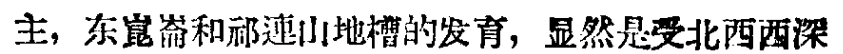
路裂影响的。

从上述覌点很, 中国地台自古生代以来, 就不 断遭受断裂的破坏, 而处于支离破碎的颀态, 分裂为

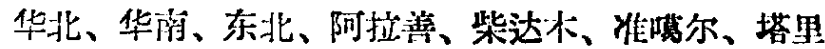
不、晒藏等台块。它大部分都被地慒包圍。另外，还

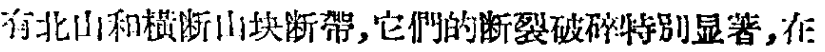
小心断块之沁，常有强烈的类似小型比情的錯动带坞

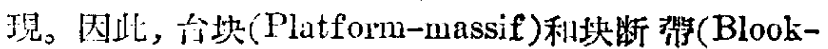

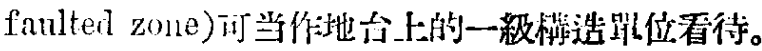

住大型合块上根据基底隆起和凹陷的不同以及

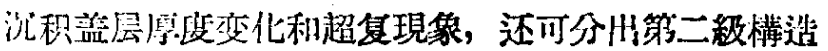
一一台背斜 (Platform anticlinorium or paraanticlis) 和台向斜(Platform synclinorium or parasynclis)。

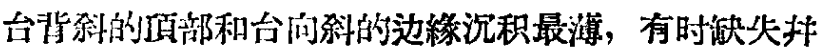

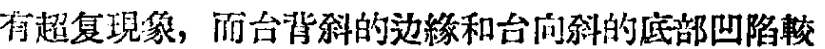
深，沉积䘡較厚。在台向科和台背斜之上，还可划分三 释棈造, 如只是简單的隆起或凹陷, 我們就把它們称 作台凹或台凹。因为形兄只是外表的状态, 不沙及本 筫,所以暂不使州台梁(長垣)等名称。但可以在前面加 上是、然、圆等形产詞。基底和盖层断裂显著的台凸或 台凹可称为骂断带(区)或凹断带(区)；基底表現断裂 而盖层表現替㿮的台凸或台四可称穹折带或山折带。

的于咽国地台比一般地台活动性大，台背科或问 到常为次一級的监起和凹陷所复杂化，因而具有复式

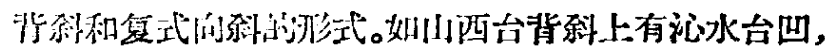
五台、吕梁、中条等台凸;鄂尔多斯台问科北部有东睲 台山。所以台背科和台向斜实际上是地台复背科和地

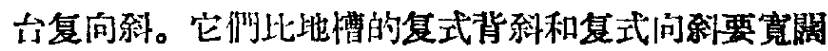
得多。此外，在四川台向攲东部（华登山以东的具有原

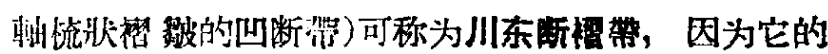

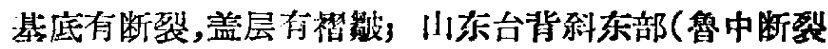
架以西他括沂河、微门湖、滥河之閒隆起区)可称为 兽西穹断带，因为它的基位和盖层都有显著的断裂。

地槽区可以进一步划分为地槽系。地槽系內的原

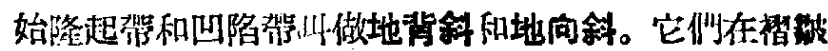

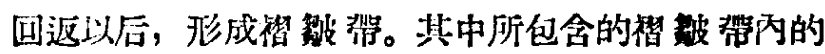
次一級權造是复式背斜和复式向斜, 可称为權特斜 (Geosynelinal anticlinorium) 和槽向斜 (Geosynclinal Synelinorium)，它們实际上是地槽复背刹、地槽复 向斜、槽背斜和慒向斜以及背科淃內的隆起和出陷，可 以称为槽凸和槽凹。

稳定性介于地慒和地台之間的过泳区在中国境内 大致有三种焱型：第一类足介于地台与地槽之間的山

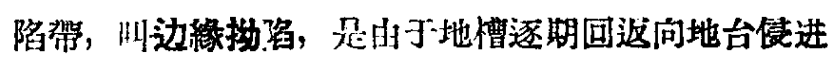
的四陷帶，所以它的基底和盖层的性賀在靠近地慒的 一洦接近地䄚犁，在致近地台的一酒接近地台犁。盖层 


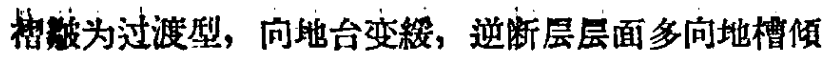

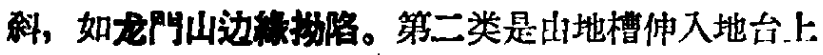

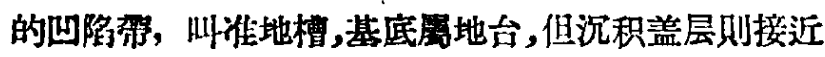
地槽梨，如与队蒙地槽相通的吉林(張广才筑)准地槽

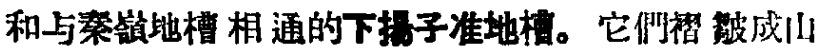

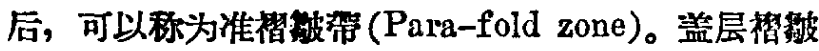
为过渡型，有时成闵状構造。第三类是地台上的强烈 四陷舒，以沉降帶。它的基底屬地台，但沉积盖层则 较厚，有时近促地槽型。柏破作用不强。禁觟形态以 过渡型和撓想为主, 如燕山沉降帶。因为它不与地槽 相通, 所以不能把它称为准地槽。我們同意 IO. A. 柯西金的意見，准地槽应归于地慒氾膟內。

按H. 史蒂雷(Stille)和 M. 凯伊(Kay) ${ }^{[1]}$ 的意見， 正地槽 (Orthogeosyncline) 是 位于地台与地台之間 的, 以做地台閔地槽 (Intercrational geosyncline); 而准地橧(Para-geosyncline) 則是位于地台之內的, 纠作地台內地槽 (Intracrational geosyncline)。因此, 我們把台块与台块之間强烈沉陷的活 动染称为 正地 橧，而正地槽伸入地台上的分枝名为准地槽，也不是潘 有根据的。史蒂雷和凱伊还进一步把正地槽分为优地 梅(Eugeosyncline)和问地橧(Miogeosyncline)。前者 是强烈下陷牛具有火山活动的地槽, 而后者則是不具 火山活动的强烈下陷带。中国的正地慒大致也可划分 为这样兩个类型, 如东秦嶺和北那速山的加里东地槽 就是优地槽; 后期在西秦嶺和南邡連山H!現的海酉地 槽则是置地慒。

至于期伊的地台內地槽中的 Exogeosyncline，㺫 可与我們的边緗拁降相比較, 他的 Autogeosyncline 和 Zengogeosyncline 相当于我鬥的推地槽。

在优地槽之外，跑伊还分出在前期优地槽基础上. 发展起来的上选优地槽(Epieugosyncline)，中国的台 被地槽就第于这类地槽。断裂地槽 (Taphrogeosyneline）在中国非常发育，中国的地槽大部分都屬于这 一类, 在前期地台的基础上，由断裂下陷而形成。至

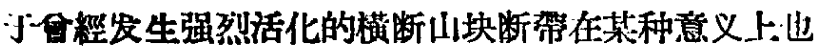
订当作断裂地槽看待。

总之, 由于大地棬造学的不断发展, 对于地槽进 行分类, 已日跲需要。但目前我国地槽地区的缷籼积 累得还不解多，因此，現在对于中国地槽进行分类少 有网难。

此外，对于前俈祳旦紀地橧的研究，因为变質岩系 中的矿产探勘工作的不断发展，也不得不提到工作日 程上来。前震且耟地槽和地台肯定是存在的，但其性 售可与以后的地台和地槽不同，就現在所保存的变动 遗䠑看来，它們显然是比以后的活动得多。因此也可 以說在太古代和元古代的期地槽是多于地台的。

至于地台，在目前看 来似乎边有加以分类的必 要。黃没清篔建議从地台中分拈准地台 (Para-plat- form)。他 ${ }^{[2]}$ 起初把四川、貴州、湖北和广西等称为准 地台，因为那里沉积盖层厚而且有稆㿮，他 ${ }^{[3]}$ 最近又把 整个华南台块和东北台块都称为准地台，認为这网个 地区的元古代基底没有全破化，而訪涊为华北台块是普 通的标准地台。但是我鬥要間一句,如果把华北合块桨 作正地台(Ortho-platform)看得，那么此較更为稳公 的俄罗斯地台又就㞗于那类地台呢?

另一些大地構造学者(謝晋晏 ${ }^{[4]} 、$ 西尼忖 ${ }^{[5]}$ 、陈 [目达 ${ }^{[6]} 、$ 別洛点索大、巴甫洛大斯基等)，则强調 地 台分裂和活化作用。霍啟多头斯基更进一此把破矿的 中国地台称为凑合地台。

根据現在已知㗄料，初步認为地台可以分为网大 类: 一是稳定型的, 如俄罗斯、北炎、南学、澳大利亞、

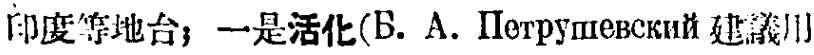
改造)型的,如中国、晒们利亞。非洲等地台。就监沉积 盖层发青的情况和基底断裂的程度，网者还圢进一步

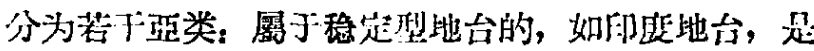
沉积盖层較不发育的地台，而俄罗折地公则是沉积盖 层比較发有的地台; 屈于活化型地台的,如非洲地台, 基底断裂比較显著，沉积盖层比較不发育，洎中国地 台可以不仅基底断裂多，井且沉积盖层也較将。

深断裂对于大地楧造发展的重要作䏚是 A. B. 㿆 偉 ${ }^{[7]}$ 首光提忺的。最近他还进一步把深断裂分为地台

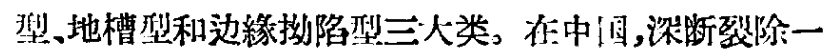
般发生在地台和地槽交界处，相当 JII.C. 沙将搬虫

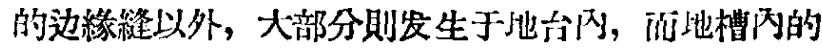
深断裂是比較少的。时于边䋹綘的发方，所以我国的 地台与地槽之閏的边緗抝陷足不发达的。我迁議把地 槽与地台之間的深断裂称为一級断裂，在台问斜与方

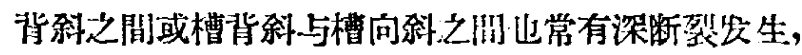
这样的断裂可称为二粐断裂，当于台台和台凹之湴或

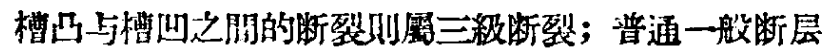

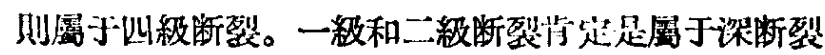

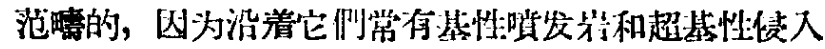

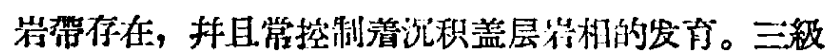
断裂除时常形成梅造單位边界外，还常成为中、酸临: 岩筷的侵入或些山孔道。

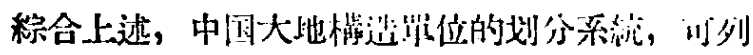
表如下。

总之，在一般的小比例人的大地構造图上除了夜

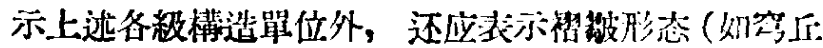

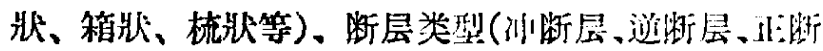

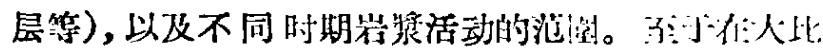

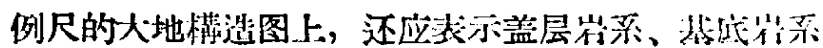

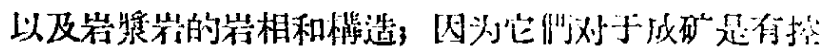

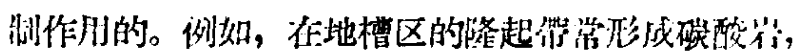

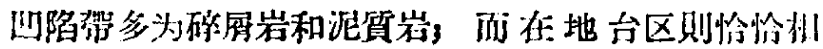
反，因顾矽卡岩型矿床在地台区和在比槽的分猚以就 


\begin{tabular}{|c|c|c|c|c|}
\hline $\begin{array}{l}\text { 活动 } \frac{\text { 与 }}{\text { 急定程度 }} \\
\end{array}$ & \multicolumn{2}{|c|}{ 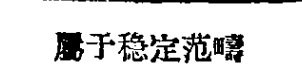 } & \multicolumn{2}{|c|}{ D于活动范略 } \\
\hline & 稳定区 & 牛稳定区 & 牛活动区 & 活 动区 \\
\hline I & 地台区 & 活化地台 & 准地槽区 & 地槽区 \\
\hline II & 台 块 & $\begin{array}{l}\text { 洁化台块 } \\
\text { 区 }\end{array}$ & 准地慒系 & 地 槽 潘 \\
\hline III & $\begin{array}{l}\text { 台背斜和 } \\
\text { 台向斜 }\end{array}$ & $\begin{array}{l}\text { 活化台背 } \\
\text { 斜和活化 } \\
\text { 台问斜 }\end{array}$ & $\begin{array}{l}\text { 准槽背斜 } \\
\text { 利准槽向 } \\
\text { 斜 }\end{array}$ & $\begin{array}{l}\text { 槽背斜和 } \\
\text { 槽向斜 }\end{array}$ \\
\hline IV & $\begin{array}{l}\text { 台凹和台 } \\
\text { 品 }\end{array}$ & $\begin{array}{l}\text { 活化台凸 } \\
\text { 和活化台 } \\
\text { 四 }\end{array}$ & $\begin{array}{l}\text { 准槽凸和 } \\
\text { 准慒凹 }\end{array}$ & $\begin{array}{l}\text { 橧凸和销 } \\
\text { 出 }\end{array}$ \\
\hline V & 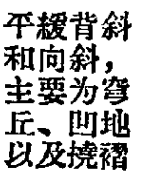 & $\begin{array}{l}\text { 短軸背斜 } \\
\text { 和问斜 }\end{array}$ & $\begin{array}{l}\text { 脣軸背斜 } \\
\text { 和向斜 }\end{array}$ & $\begin{array}{l}\text { 綫泾紧湿 } \\
\text { 背斜和向 } \\
\text { 斜 }\end{array}$ \\
\hline
\end{tabular}

不同。此外，地槽区和地台区断裂紫內的內生矿非多
成带爿分分杀，而地台㐫的則多成杯狀或片狀，这也是我 僻稀制大比例尺大地構造图时应加注意的。

必須指出, 在一張大地構造图內不能把所有的構 造細节及其发展过程都无遺地表示山来。因此, 在必 要的时候, 还应加糄一些輔助性的附图, 如基底以及 不同时期的沉积盖层的等深棧图、各时期的岩相分布 和厚度图，以及各主要構造阶段的古構造图等。

[1] Marshell Kay: North American Geosynelines, Mem. 48, USA, 1951.

[2] 燕汲清(1954): 中国区域地筫的特征，地箕学报， 34 炝, 3 期, 1954 年。

[3] 黄汲清(1958): 編制中国大地粠造图的若干澺見及 簡則(草案), 1958 年。

[4] IO. M. 謝音曼(1937)：論中国地盾的历史、地苋 发展的規律性与区域大地構造, 科学出版社, 1955年。

[5] B. M. 西尼村 (1948): 中国陆台的掼造及其发展， 周上。

[6] 陈国达(1956)：中国地台“活化区的实例讲着重时 論华夏古陆”問題，地筫学报，36 卷，3期, 1956 年。

[7] A. B. 翌偉: 深大断裂的特点、分类及其在究间 上的分右，地筫譯䂭，11 期，1956 年。

\section{苏联科学家論宇宙火箭 和宇宙飞行}

編者按：浫联守宙火箭上天，使疾勁的东风进一步压倒西风。这是人类放射到 地球引力范圍之外的守宙空間的第一个火箭, 它不仅为人类带来大量的有关宇宙空 間的宝貴資料, 而且也为星际航行和开发球以及其他行湦打汧了道路。最近, 苏

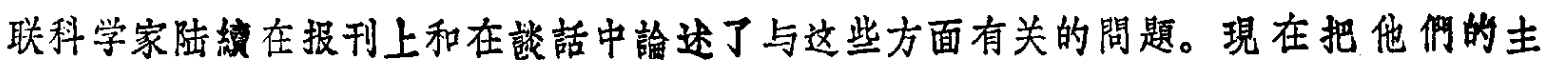
要諭点整理荣輯如下。

\section{苏联的宇宙火箭是現代 科学技术上的奇跡}

布拉岡拉沃夫(苏联科学院院士)：空崩的速度、 惊人的重星和完全准确的飞行控例，是苏联火箭技术

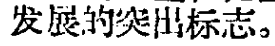

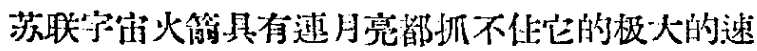
度，因此它不会变成永久葍繞月球运轉䋇卫星，它將 越过月亮繼續作太阳系的宇宙中飞行。这是世界上第

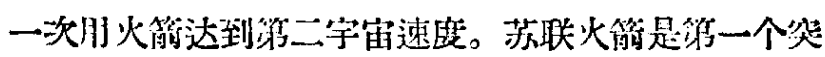
破地球引力的地球上的物体。这是苏联火简技术发展 的第一个絴朋标志，苏联科学和技术已經走在美国前 面。大家知道，美国在这方西作了几次尝陚，都长收 了; 歨年10月美国向月球发射的火简自于地球引力的 影响沟有达到月球地区就鉒落了。

第二个表归苏联佔先的合人信服的标志是, 以弚
所发射的苏联人造卫星的重量和將近一吨牛的月球火 简的重量。而美国最后一个人造卫星的重量还赶不上 苏联第一个人造卫星。

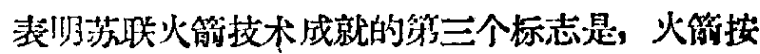

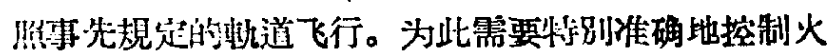
简。只要火简最后一刹进入軌道的时間稍微差錯几分 剑或速度上有細小差錯,就会导致失敗。美国1958年10 月发射的月球火箭在速度上只失去了百分之二便遭到 火敗。苏联和学家和工程师們已經解决了控制火箱飞 行的最艰难的任务。仪器工作的准确性是苏联火籍技 术的異常重要的新进步。宇宙空間没有不可能达到的 地方。当然, 这需要时間, 但是不必等待多久了。

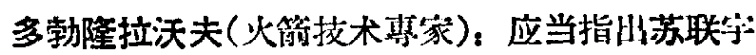
访火简的五人体积。苏联第三个卫星就有約四公尺 椟、二公尺的直徑(不算突出的天的)，而宇宙火箱的 重量还超过这个卫是，作这样大和重的火箭上完全可 